\title{
Accident Tolerant Nuclear Fuels and Cladding Materials
}

\author{
INDRAJIT CHARIT ${ }^{1,2}$ \\ 1.-Department of Chemical and Materials Engineering and Nuclear Engineering Graduate Pr- \\ ogram, University of Idaho, Moscow, ID 83844, USA. 2.-e-mail: icharit@uidaho.edu
}

\begin{abstract}
Safety and reliability of nuclear power plants is of paramount importance. In 2011, the devastating earthquake and subsequent tsunami in Japan led to severe damage to the boiling water reactors (BWRs) of the Fukushima-Daiichi nuclear power plant. Zircaloy-2 was the alloy used as cladding materials in those affected reactors. From the early days of power reactors, zirconium alloys were chosen for light water reactors (LWRs) fuel-cladding applications because of their low neutron absorption crosssection for thermal neutrons, good thermal conductivity, high melting point $\left(\sim 1830^{\circ} \mathrm{C}\right)$ and adequate corrosion resistance. Zircaloy-2 and -4 have remained the mainstay LWR fuel-cladding alloys for several decades. Further improvements in the corrosion and mechanical properties of zirconium alloys have been obtained to meet the requirements of higher burnup, higher fuel duty and longer inreactor service with the development of alloys such as Zirlo and M5. However, the reason for moving away from zirconium for accident tolerance is the severe degradation of zirconium properties at elevated temperatures. In a loss-of-coolant accident (LOCA) event such as at Fukushima, the core becomes exposed to steam rather than the coolant (water), and the decay heat (from $\beta^{-}, \beta^{+}$, and $\gamma$ decays of short-lived isotopes) being produced in the core continues to heat up the fuel and cladding. ${ }^{1}$ Above $850^{\circ} \mathrm{C}$, the alpha phase (HCP) of zirconium alloys undergoes polymorphic transformation to the beta phase (BCC), which is completed at about $980^{\circ} \mathrm{C}$. The oxidation rate of $\mathrm{Zr}$-alloy increases rapidly with increasing temperature at $>800^{\circ} \mathrm{C}$ to release hydrogen through an extremely exothermic reaction, which leads to the possibility of a hydrogen explosion. Neither the loss of strength due to the polymorphic transformation nor the rapid oxidation/corrosion at higher temperatures can be alleviated by improved alloy design or improved
\end{abstract}

Indrajit Charit is the JOM advisor for the Nuclear Materials Committee of the TMS Structural Materials Division and the guest editor for the topic, Accident Tolerant Nuclear Fuels and Cladding Materials, in this issue. processing of zirconium alloys. If the situation is left unchecked, it can eventually lead to other catastrophic consequences such as core melting.

In the aftermath of the incident, the United States (U.S.) Congress directed the Department of Energy (DOE) to initiate a focused effort to improve accident tolerance of LWRs. The Advanced Fuels Campaign under the Fuel Cycle R\&D Program took charge of coordinating this effort. In the following years, extensive R\&D has been ongoing by bringing together national laboratories, academia, and industries for developing accident-tolerant nuclear fuel and cladding forms for use in LWRs.

Alternative accident-tolerant fuel (ATF) forms should have the following characteristics: ${ }^{2}(1)$ maintain high fuel safety and reliability under normal LWR operating conditions; (2) delay fission product release and fuel meltdown and improved reaction kinetics with steam and slower hydrogen generation under off-normal conditions; and (3) possess adequate strength at higher temperatures for longer times to maintain the fuel assembly geometry and integrity. According to the U.S. DOE performance metric report, any potential ATF system should be evaluated for all the possible 'performance regimes' such as: fabrication and manufacturability (including licensibility); normal operations and anticipated operational occurrences; postulated accidents (design basis); severe accidents (beyond design basis); and ease of used fuel storage/transport/disposition. Basically, the purpose of using accident-tolerant fuel/cladding systems is to impart greater safety margins by delaying the onset of severe core degradation, leading to more coping time available to implement mitigation strategies during an accident situation. $^{3}$

Several accident-tolerant fuel-cladding concepts such as SiC-based composites, aluminum-bearing ferritic steels, refractory alloy-based materials and coated zirconium alloys among others are being investigated. ${ }^{4}$ Uranium silicide fuels with greater thermal conductivity and high fissile density are of interest as alternatives to the currently used 
uranium dioxide $\left(\mathrm{UO}_{2}\right)$. There is also interest in fully ceramic microencapsulated (FCM) fuel forms as ATF.

The TMS Nuclear Materials Committee has been active in organizing symposia and coordinating annual publications of articles in the nuclear materials field of current interest. In this $J O M$ special topic, the first four articles are on the accidenttolerant cladding materials and the last three are based on uranium silicide fuels. Unfortunately, due to limited space and time available, not all possible accident-tolerant fuels and cladding materials could be covered in this issue. However, the articles do include the most active, current research areas within the topic. Among many other projects, a Georgia Tech-led multi-institutional team under a DOE-funded Integrated Research Program (IRP) developed a conceptual design of an Integral Inherently Safe LWR ( $\left.{ }^{2} \mathrm{~S}-\mathrm{LWR}\right)$ in which $\mathrm{U}_{3} \mathrm{Si}_{2}$ as the ATF fuel and APMT (Fe-22Cr-5Al-3Mo) as the ATF cladding material were considered. ${ }^{5}$ Although the articles here have been authored by researchers based in the U.S., international research on ATF materials has also been quite active. ${ }^{6}$

The first article titled, "Versatile Oxide Films Protect FeCrAl Alloys Under Normal Operation and Accident Conditions in Light Water Power Reactors," by Raul Rebak is on the assessment of oxidation resistance of $\mathrm{FeCrAl}$ cladding alloy. It was found that $\mathrm{Al}$ does not participate in the passive film formed in high-temperature water and $\mathrm{Al}$ may never be needed under the normal operation conditions. However, if a LOCA occurs, the $\mathrm{Al}$ present in the alloy will form a protective alumina layer that will resist the attack by superheated steam. At higher temperatures, $\mathrm{Al}$ offers the protection to the tubes until their melting point. Rebak describes the synergistic effect between $\mathrm{Cr}$ and $\mathrm{Al}$ in $\mathrm{FeCrAl}$ alloy to make the material ideal for both normal and offnormal situations.

The second article entitled, "Oxidation Kinetics of Ferritic Alloys in High-Temperature Steam Environments," by Stephen Parker et al., describes a comparative study of elevated temperature oxidation kinetics between various ferritic steels and Zircaloy-2, obtained by thermogravimetry. Aluminum-bearing ferritic steels such as MA 956 and APMT exhibited the best high-temperature oxidation resistance in comparison to other alloys investigated including Zircaloy-2 because of the stable alumina scale formation.

The third article entitled, "Laser and Pressure Resistance Weld of Thin-Wall Cladding for LWR Accident Tolerant Fuels," by Jian Gan et al., discusses recent welding research utilizing both laser and pressure resistance welding techniques to develop joints between aluminum-containing ferritic steel cladding and endcaps. Initial results show promise in providing hermetic sealing to the weld joints.
The fourth article entitled, "Development of Cold Spray Coatings for Accident Tolerant Fuel Cladding in Light Water Reactors," by Benjamin Maier et al., describes an approach for developing accident-tolerant coatings of $\mathrm{Zr}$ alloy cladding instead of eliminating the use of $\mathrm{Zr}$ alloys as fuel cladding altogether. The reported research is a product of a collaborative effect between the University of Wisconsin-Madison and Westinghouse Electric Company. The study applied a cold spray technique to create three types of coatings, $\mathrm{Cr}, \mathrm{FeCrAl}$ coating with Mo interlayer, and $\mathrm{Ti}_{2} \mathrm{AlC}$, on $\mathrm{Zr}$-alloy cladding tubes as substrate. The study demonstrated that the elevated temperature oxidation resistance of the $\mathrm{Zr}$ alloy cladding can be significantly improved, and future qualification testing will further assess its actual use in LWRs.

The fifth article entitled, "Mechanical Properties of Uranium Silicides by Nanoindentation and Finite Elements Modeling," by Ursula Carvajal-Nunez et al., evaluates the hardness and modulus of various uranium silicide fuels using quasi-static and continuous stiffness measurements using nanoindentation and their bulk hardness using microindentation. Finite element modeling was also employed to validate the nanoindentation data for $\mathrm{U}_{3} \mathrm{Si}_{2}$ and predict yield strength. This preliminary work may aid in the future development of these accident-tolerant fuels.

The sixth article entitled, "Effect of High Si Content on Fuel Microstructure," by Jhonathan Rosales et al., reports fabrication of uranium-silicide fuels with two different concentrations of silicon via conventional powder metallurgy and their microstructural characterization using scanning electron microscopy, transmission electron microscopy and x-ray diffraction. Different phases were detected. Further optimization of the fuel composition and processing will be needed for minimizing deleterious phases and improving fuels with better performance.

The seventh article entitled, "Microstructure Evaluation of a $\mathrm{U}_{3} \mathrm{Si}_{2}$ Fuel Pin Fabricated via Arc Melt Gravity Drop Casting," by Hoggan and Harp, describes an effort to fabricate $\mathrm{U}_{3} \mathrm{Si}_{2}$ via arc melting and gravity drop casting. Optical microscopy and SEM/EDS techniques were used to characterize the microstructure developed. The casting process needs to be carefully controlled for optimum performance because of significant tungsten contamination coming from the arc melting electrode. This demonstrates that more work is needed in the area of silicide fuel fabrication.

The U.S. Department of Energy has the goal of inserting an accident-tolerant lead fuel assembly in a commercial power reactor by mid-2022. With the ongoing R\&D efforts and interest of companies, this may as well be accomplished sooner. It is our hope that this special issue will enlighten the readers 
with a greater understanding of the diverse research activities taking place in the area of 'accident-tolerant fuels and cladding materials.'

The following papers are published under the topic "Accident Tolerant Nuclear Fuels and Cladding Materials" in the February 2018 issue (vol. 70, no. 2) of JOM and can be accessed via the JOM page at http://link.springer.com/journal/11837/70/2/page/ 1 .

- "Versatile Oxide Films Protect FeCrAl Alloys Under Normal Operation and Accident Conditions in Light Water Power Reactors" by Raul B. Rebak.

- "Oxidation Kinetics of Ferritic Alloys in HighTemperature Steam Environments" by Stephen S. Parker, Joshua T. White, Peter Hosemann, and Andrew Nelson.

- "Laser and Pressure Resistance Weld of ThinWall Cladding for LWR Accident Tolerant Fuels" by Jian Gan, Nathan Jerred, Emmanuel Perez, and D.C. Haggard.

- "Development of Cold Spray Coatings for Accident Tolerant Fuel Cladding in Light Water Reactors" by Benjamin Maier, Hwasung Yeom, Greg Johnson, Tyler Dabney, Jorie Walters, Javier Romero, Hemant Shah, Peng $\mathrm{Xu}$, and Kumar Sridharan.
- "Mechanical Properties of Uranium Silicides by Nanoindentation and Finite Elements Modeling" by Ursula Carvajal-Nunez, Mohamed S. Elbakhshwan, Nathan A. Mara, Joshua T. White, and Andrew T. Nelson.

- "Effect of High $\mathrm{Si}$ Content on $\mathrm{U}_{3} \mathrm{Si}_{2}$ Fuel Microstructure" by Jhonathan Rosales, Isabella J. van Rooyen, Subhashish Meher, Rita Hoggan, Clemente Parga, and Jason Harp.

- "Microstructure Evaluation of a $\mathrm{U}_{3} \mathrm{Si}_{2}$ Fuel Pin Fabricated via Arc Melt Gravity Drop Casting" by Rita Hoggan and Jason M. Harp.

\section{REFERENCES}

1. P. Wray and J. Marra, Am. Ceram. Soc. Bull. 90, 24 (2011).

2. S. Bragg-Sitton, B. Merrill, M. Teague, L. Ott, K. Robb, M. Farmer, R. Montgomery, C. Stanek, M. Todosow, and N. Brown, Advanced Fuels Campaign Light Water Reactor Accident Tolerant Fuel Performance Metrics: Fuel Cycle Research \& Development, U.S. DOE LWR ATF Performance Metrics Report (2014).

3. B.A. Pint, K.A. Terrani, Y. Yamamoto, and L.L. Snead, Metall. Mater. Trans. E 2, 190 (2015).

4. S.J. Zinkle, K.A. Terrani, J.C. Gehin, L.J. Ott, and L.L. Snead, J. Nucl. Mater. 448, 374 (2014).

5. B. Petrovic, Nucl. Eng. Int. 1, 26 (2014).

6. S. Bragg-Sitton, Overview of international activities in accident tolerant fuel development for light water reactors, in IAEA Technical Working Group on Fuel Performance and Technology (U.S. Department of Energy, 2014). 